\title{
Post-discharge extended care contributes to the disease control of patients with COPD: a Chinese study
}

This article was published in the following Dove Press journal: International Journal of COPD

Min $\mathrm{Li}^{\prime}$

Rong $\mathrm{Hu}^{2}$

Xiaoyang $\mathrm{Liu}^{3}$

Shuping $\mathrm{TaO}^{4}$

Biaoxue Rong ${ }^{1,5}$

'Department of Respiratory Medicine, Shenmu Hospital, Shenmu, Shaanxi, China; ${ }^{2}$ Department of Nursing, Shenmu Hospital, Shenmu, Shaanxi, China; ${ }^{3}$ Department of Surgery, Shenmu Hospital, Shenmu, Shaanxi, China; ${ }^{4}$ Department of Respiratory Medicine, Gansu Provincial Hospital, Lanzhou, Gansu, China; ${ }^{5}$ Department of Respiratory Medicine, First Affiliated Hospital, Xi'an Medical University, Xi'an, Shaanxi China
Correspondence: Biaoxue Rong Department of Respiratory Medicine, Shenmu Hospital, Shenmu, 719300, Yulin City, Shaanxi, China

Tel +86 I 5349260656

Email research568rbx@yeah.net
Background: The aim of this study was to evaluate the efficacy of extended care in patients with COPD.

Patients and methods: A total of 140 patients with GOLD-2 to -4 of COPD were included in final analysis. The care efficacy was evaluated by the St George's Respiratory Questionnaire 12-item General Health Questionnaire (GHQ-12), pulmonary function test and blood gas analysis.

Results: The extended care improved the activity ability of COPD patients, relieved the clinical symptoms as well as reduced the impact degree of COPD to daily life $(P<0.05)$. In addition, the extended care improved the mental health condition of patients with COPD compared with usual care $(P<0.05)$. Moreover, the extended care improved the ventilation function of COPD patients, reduced the acute exacerbation rate and improved the blood gas levels compared with the usual care $(P<0.05)$.

Conclusion: The extended care improves the quality of life, respiratory function and the mental health condition of patients with COPD after discharge, indicating that it contributes to the disease control of patients with COPD.

Keywords: extended care, COPD, disease control

\section{Introduction}

COPD is a pulmonary disease with irreversible air inflow limitation and is induced by damage to the airway and lung parenchyma due to chronic inflammation. ${ }^{1}$ Although it cannot be reversed, medical treatment can help to control symptoms and minimize further damage. ${ }^{2}$ COPD is often exacerbated by acute inflammatory insults, such as lung infections (viral and bacterial) and air pollutants, which seriously affect the patient's quality of life. ${ }^{3}$ Since the 1990 s, early follow-up has been applied to patients with chronic diseases, and a scientific and detailed nursing intervention plan has been developed through the patient's assessment. ${ }^{4,5}$ The conceptual model of extended care (continuity of nursing) was developed by Haggerty et al, suggesting that continuity refers to the degree of coherence and connectivity of a range of separate health service events accepted by the patients, as well as the degree of consistency with the patient's medical needs and personal background. ${ }^{6,7}$ Extended care is a new nursing pattern, which is designed through a series of actions to ensure that patients receive different levels of continuous care in different health care sites (from hospital to home). ${ }^{7,8}$ The purpose of extended care is to help improve the clinical treatment efficacy and the quality of life of patients with COPD. 
In 2012, China's Nursing Career Development Program proposes that the extended care would become one of the key tasks of health work in China. ${ }^{9}$ Today, although the recovery rate of chronic diseases in Chinese patients has improved and hospitalization has declined, there are still many problems worthy of further discussion, such as extended treatment and care for chronic diseases. In this study, we investigated the efficacy of post-discharge extended care to patients with moderate-to-severe COPD.

\section{Patients and methods}

\section{Patients}

From January 2016 to December 2017, a total 156 patients confirmed with GOLD-2 to -4 of COPD were involved in the study (Gansu Provincial Hospital, Lanzhou, China; First Hospital, Xi'an Medical University, Xi'an, China; and Shenmu Hospital, Shenmu, China). The study was approved by the research ethics committee of the abovementioned hospitals, respectively, and all the patients signed the informed consent before including the study. This study is a non-randomized observational study. According to the patient's discharge order, the patients were alternately assigned to the observation group and the control group and received different care measurements. The length of observation is 3 months. Of 156 patients, 77 patients received usual care. The other 79 patients were treated by extended care. Finally, 140 patients entered the final analysis (extended care group $=70$; usual care group) (Figure 1). Clinical information and general data of the included patients are shown in Table 1.

\section{CONSORT statement}

The patient's enrollment did not follow the principle of random distribution, just depended on the order of discharge and the patient's will. All patients, data collectors and statisticians were not blinded to assignment. For patient safety, investigators did not perform blind and hidden assignments. In addition, we also conducted an intention-to-treat analysis and a bias analysis of result report.

\section{Inclusion criteria of patients}

Inclusion criteria are as follows: 1) patients with COPD history were diagnosed by the pulmonary function test according to the diagnostic criteria of GOLD. ${ }^{10,11}$ After inhalation of bronchodilator, the value of $\mathrm{FEV}_{1} / \mathrm{FVC}$ of patient that was $<0.70$ indicated that the airflow is limited, and the diagnosis of COPD was confirmed; 2) patients with no history or examination records for other major diseases; and 3) patients enrolled were willing to participate in the study and they could complete the entire program with compliance.

\section{Exclusion criteria of patients}

It is not permissible to enter the study when the patient merges or exhibits any of the following terms: 1) COPD patients with bronchial asthma, tuberculosis, pneumonia, bronchial pneumonia, lung cancer and other pulmonary organic diseases; 2) COPD patients with severe cardiovascular, cerebrovascular and neurological diseases or liver and kidney dysfunctions; and 3) COPD patients with mental illness, cognitive dysfunction or existing exchange disorders.

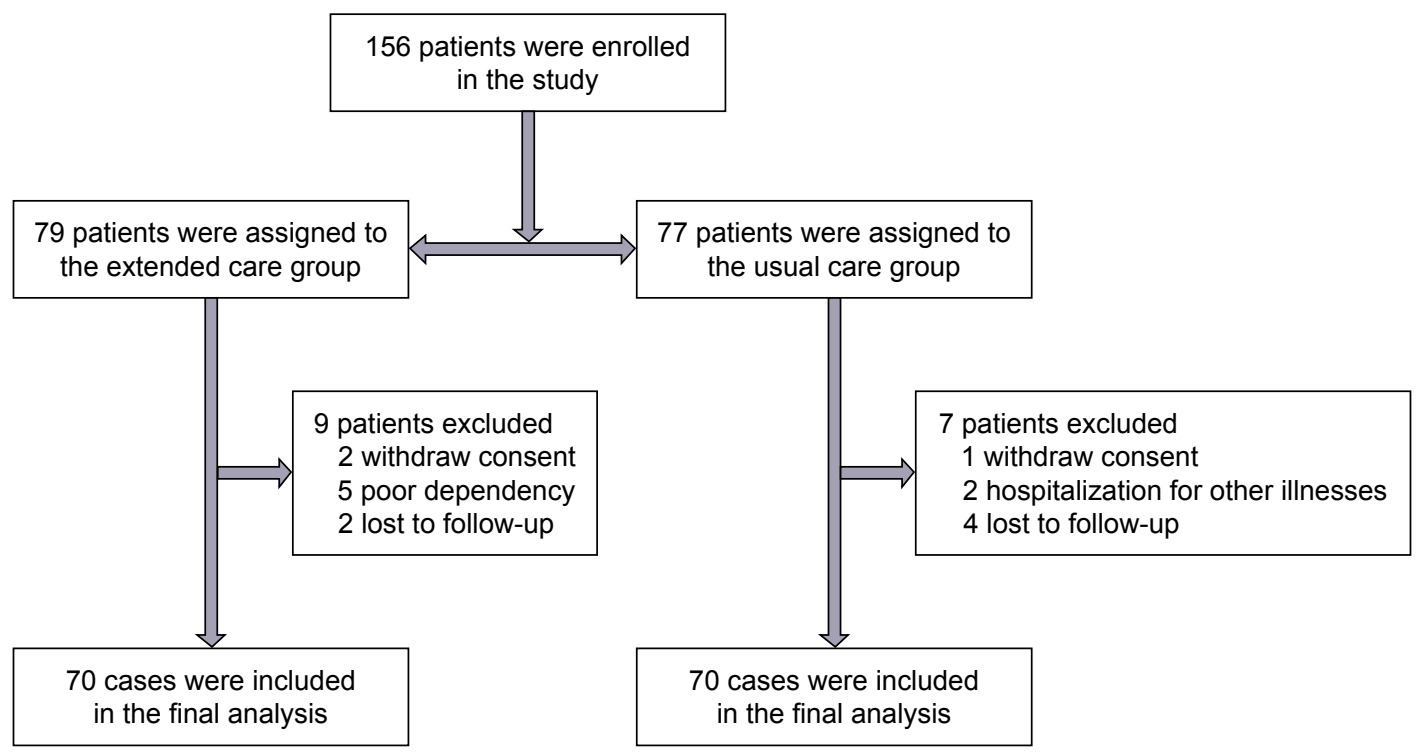

Figure I Patient flow diagram of this study. 
Table I Clinical information and general data of the included patients (I 40 cases)

\begin{tabular}{|c|c|c|c|}
\hline Items & Classification & Usual care group (70), n (\%) & Extended care group (70), n (\%) \\
\hline \multicolumn{4}{|l|}{ Gender } \\
\hline & Male & $40(57.1)$ & $44(62.9)$ \\
\hline & Female & $30(42.9)$ & $26(37.1)$ \\
\hline \multicolumn{4}{|l|}{ Smoking } \\
\hline & Yes & $43(61.4)$ & $39(55.7)$ \\
\hline & No & $27(38.6)$ & $31(44.3)$ \\
\hline \multicolumn{4}{|l|}{ Education level } \\
\hline & Junior high school and below & $24(34.3)$ & $26(37.1)$ \\
\hline & Senior high school & $28(40)$ & $24(34.3)$ \\
\hline & University and above & $18(25.7)$ & $20(28.6)$ \\
\hline \multicolumn{4}{|l|}{ Monthly economic income } \\
\hline & $<3,000$ RMB & $18(25.7)$ & $22(31.4)$ \\
\hline & $\geq 3,000$ and $\leq 5,000$ RMB & $28(40)$ & $24(34.3)$ \\
\hline & $>5,000 \mathrm{RMB}$ & $24(34.3)$ & $24(34.3)$ \\
\hline \multicolumn{4}{|l|}{ Classification of lung dysfunction } \\
\hline & Moderate GOLD-2 & $38(54.3)$ & $36(5 \mid .4)$ \\
\hline & Severe GOLD-3 & $28(40)$ & $32(45.7)$ \\
\hline & Extremely severe-GOLD-4 & $4(5.7)$ & $2(2.8)$ \\
\hline
\end{tabular}

Note: RMB, Chinese currency unit.

\section{Classification for COPD}

We determined the classification of COPD according to the GOLD as follows: ${ }^{12}$ 1) GOLD-2 of COPD, the $\mathrm{FEV}_{1}$ expected value is $\geq 50 \%$, but $<80 \%$; 2) GOLD- 3 of COPD, the FEV expected value is $\geq 30 \%$, but $<50 \%$; and 3 ) GOLD- 4 , the $\mathrm{FEV}_{1}$ expected value is $<30 \%$.

\section{Terms for withdrawal of patients and intention-to-treat analysis}

Withdrawal conditions are as follows: 1) patients take the initiative to withdraw from the study with a strong attitude; 2) researchers believe that it may lead to serious results if the patients continue to participate in the research; and 3 ) during the follow-up procedure, the patients have to withdraw from the study due to death or other objective reasons.

\section{Interventions of different groups}

Extended care includes the following measures: health guidance, helping to quit smoking, guiding medication, respiratory exercise, physical training, long-term home oxygen therapy, psychological care, family visits, social support and nutritional support. The details are shown in Table 2. Usual care only includes health guidance and long-term home oxygen therapy. Both groups of patients received the same doctor's advice and prescribed medications to control disease, including $\beta 2$ adrenergic receptor agonists, $\mathrm{M}$ receptor blockers and glucocorticoid inhalants. There was no significant difference between the two groups $(P>0.05)$.

\section{Observe indicators}

\section{Evaluation of subjective efficacy}

We used the St George's respiratory questionnaire (SGRQ) ${ }^{13}$ to evaluate the subjective efficacy. SGRQ mainly includes 50 evaluation items, which can be divided into three items

Table 2 Nursing measurement for usual care group vs extended care group $(M \pm S D)$ ( 140 cases)

\begin{tabular}{l|l|l}
\hline Interventions for care & $\begin{array}{l}\text { Extended } \\
\text { care (70) }\end{array}$ & $\begin{array}{l}\text { Usual care } \\
(\mathbf{7 0 )}\end{array}$ \\
\hline Health guidance $^{\mathrm{a}}$ & Yes & Yes \\
Helping to quit smoking $^{\mathrm{b}}$ & Yes & No \\
Guiding medication $^{\mathrm{c}}$ & Yes & No \\
Respiratory exercise $^{\mathrm{d}}$ & Yes & No \\
Physical training $^{\mathrm{e}}$ & Yes & No \\
Long-term home oxygen therapy $^{\mathrm{f}}$ & Yes & No \\
Psychological care $^{g}$ & Yes & No \\
Family visits $^{\mathrm{h}}$ & Yes & No \\
Social support & Yes & No \\
Nutritional support & Yes & No \\
Contact a doctor when the patient is & Yes & Yes \\
not feeling well & & \\
\hline
\end{tabular}

Notes: aPatient or family members are required to receive health guidance, including disease observation, medication, diet, activity, family rehabilitation training, referral time, self-care guidance, etc. ' ${ }^{\circ}$ Guide and help patients quit smoking. 'To guide patients to use drugs correctly such as bronchodilators or glucocorticoids. 'Patients are required to receive a respiratory exercise on COPD, including shrink lip breathing and abdominal breathing, which is to help the patients master the correct breathing

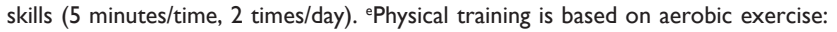
quantitative walking and upper limb movement ( 15 minutes/time, 2 times/day). fInstruct patients to receive long-term home oxygen therapy; time $\geq 5$ hours/day, oxygen flow I-2 L/min. sPsychological care: the researchers pay close attention to the patient's mental state and give psychological counseling, encourage and care for patients. 'Family visits are performed for each patient (I time/every week). The contents of follow-up include the inquiry of mental state, physical examination, the use of drugs and the situation of acute exacerbations. Providing effective social support (through psychologist). Providing scientific nutritional support to patients (through nutritionist).

Abbreviation: $M$, mean. 
to measure as follows: activity ability, clinical symptoms and the impact degree of COPD to daily life. The score range of every item is from 0 to 100 points. The higher the score, the worse the patient's condition is. The mental health condition of patients was assessed by the 12-item General Health Questionnaire (GHQ-12), ${ }^{14}$ which mainly includes 12 test items, and each test item is set to the following four options: "fully", "as usual", "occasional" and "completely unable to complete". The score for the answers "fully" and "as usual" is 0 , and the score for the answers "occasional" and "completely unable to complete" is 1 . The total score of the questionnaire was 12 points. The higher the score, the worse the patient's mental health is.

\section{Evaluation of objective efficacy}

The lung function of patient was tested by three investigators for three times, we took an average of three measurements. The measurement items included $\mathrm{FEV}_{1}$, maximum vital capacity (FVC) and $\mathrm{FEV}_{1} / \mathrm{FVC}$ values. The incidence of acute exacerbation of COPD in both groups was assessed in 3 months. Acute exacerbation of COPD is defined as the sudden worsening of the patient's respiratory symptoms beyond normal dayto-day variations. ${ }^{15,16}$ Meanwhile, we collected the patient's arterial blood in the morning for blood gas detection. The oxygen partial pressure $\left(\mathrm{PaO}_{2}\right)$ and the carbon dioxide partial pressure $\left(\mathrm{PaCO}_{2}\right)$ were the main observation indicators.

\section{Statistical methods}

We used the SPSS 21.0 software package (SPSS Inc., Chicago, IL, USA) to perform statistical analysis. The count data are expressed in terms of constituent ratio (\%), and the statistical results of the measurement data are expressed as mean $\pm \mathrm{SD}(\mathrm{M}$ $\pm \mathrm{SD})$. The comparisons of SGRQ scale score, GHQ-12 score and blood gas indicators were analyzed using the Student's $t$-test, one-way ANOVA and Kruskal-Wallis test. The comparison for the incidence of acute exacerbation of COPD was performed by the chi-squared test. All measurement data were analyzed by the normality test. All data statistics were conducted using a bilateral test, and statistical significance was set at $P<0.05$.

\section{Results}

\section{Extended care promotes the activity ability of patients with COPD}

As shown in Table 3, after intervention the score of activity in the extended care group $(60.24 \pm 6.11)$ was lower than that in the usual care group (72.38 \pm 4.57$)$, which indicated that the extended care promoted the activity ability of patients with COPD $(P<0.05$; Figure $2 \mathrm{~A})$.

\section{Extended care mitigates the clinical symptoms of patients with COPD}

As shown in Table 3, after intervention the symptom score in the extended care group $(52.53 \pm 2.84)$ was decreased compared with the usual care group (67.26 \pm 3.78 ), which indicated that the extended care contributed to control the clinical symptoms of patients with COPD $(P<0.05)$ (Figure 2A).

\section{Extended care reduces the impact degree of COPD to daily life in patients with COPD}

As shown in Table 3, after intervention the score of impact degree in the extended care group displayed an obvious decrease $(55.83 \pm 7.22)$ compared to the usual care group (62.06 \pm 6.76$)$, which indicated that the extended care decreased the impact degree of COPD to daily life of patients $(P<0.05$; Figure 2A).

\section{Intra-group comparison of different intervention groups}

For in-group comparisons (pre-intervention vs postintervention), the usual care group did not show statistical difference $(P>0.05)$, but the results from the extended care group showed that compared to before intervention the extended care significantly promoted the activity ability of patients with COPD $(P<0.05)$, relieved the clinical symptoms of patients $(P<0.05)$ and decreased the impact degree of COPD to daily life of patients $(P<0.05)$.

Table 3 Comparison of SGRQ scale score between before intervention and after intervention for usual care group vs extended care group ( $M \pm S D$, points)

\begin{tabular}{|c|c|c|c|c|c|c|}
\hline \multirow[t]{2}{*}{ Items } & \multicolumn{2}{|c|}{ Usual care group (70 cases) } & \multirow[t]{2}{*}{$P$-value } & \multicolumn{2}{|c|}{ Extended care group (70 cases) } & \multirow[t]{2}{*}{$P$-value } \\
\hline & Before intervention & After intervention & & Before intervention & After intervention & \\
\hline Activity scores & $76.46 \pm 5.12$ & $72.38 \pm 4.57$ & $>0.05$ & $81.23 \pm 3.89$ & $60.24 \pm 6.1 \mathrm{I}^{\mathrm{a}}$ & $<0.05$ \\
\hline Symptom scores & $70.73 \pm 4.33$ & $67.26 \pm 3.78$ & $>0.05$ & $71.91 \pm 7.22$ & $52.53 \pm 2.84^{b}$ & $<0.05$ \\
\hline Impact scores & $68.99 \pm 3.29$ & $62.06 \pm 6.76$ & $>0.05$ & $69.92 \pm 9.56$ & $55.83 \pm 7.22^{c}$ & $<0.05$ \\
\hline
\end{tabular}

Notes: after intervention, the comparison of extended care with usual care on activity score $(P<0.05)$. ${ }^{b} A f t e r$ intervention, the comparison of extended care with usual care on activity score $(P<0.05)$. 'After intervention, the comparison of extended care with usual care on activity score.

Abbreviations: M, mean; SGRQ, St George's Respiratory Questionnaire. 

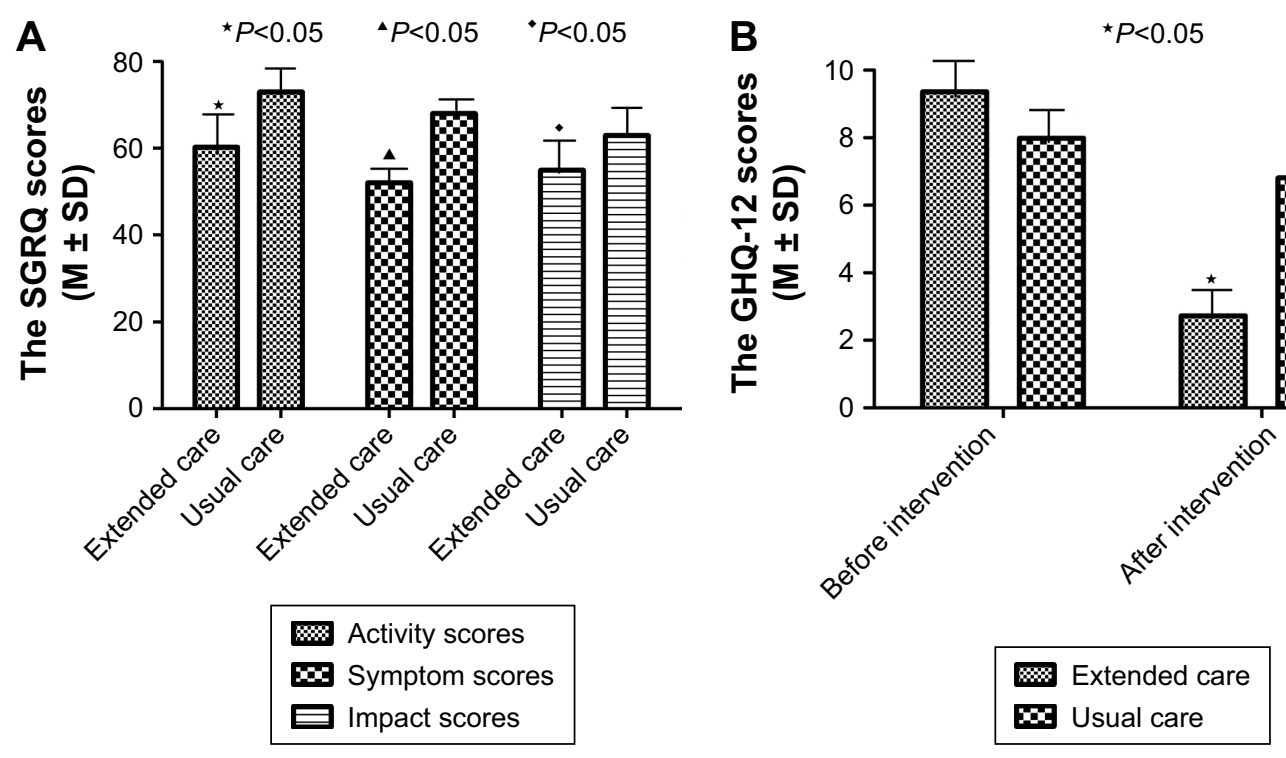

Figure 2 Evaluation of efficacy of extended care and usual care patients with COPD after discharge.

Notes: (A) Extended care promoted the activity ability, mitigated the clinical symptoms as well as reduced the impact degree of COPD to daily life in patients with COPD $(P<0.05)$. (B) Extended care improved the psychological health of patients with GOLD-2 to -4 of COPD $(P<0.05)$.

Abbreviations: GHQ-12, 12-item General Health Questionnaire; M, mean; SGRQ, St George's Respiratory Questionnaire.

\section{Extended care improves the mental health condition of patients with COPD}

As shown in Table 4, there was no significant difference in GHQ-12 scores between two groups before intervention $(P>0.05)$. However, after the intervention, the score of the extended care group $(2.73 \pm 0.59)$ was significantly lower than that of the usual care group $(6.81 \pm 0.95)$, which indicated that the extended care improved the mental health condition of patients with $\mathrm{COPD}(P<0.05$; Figure 2B). In addition, compared to before intervention the extended care significantly promoted the mental health condition of patients with COPD $(P<0.05$; Figure 2B).

\section{Extended care contributes to improve the ventilation function of patients with GOLD-2 to -4 of COPD}

As shown in Table 5, after intervention, the value of $\mathrm{FEV}_{1}$ in the extended care group $(0.57 \pm 0.09)$ was higher than that in the usual care group $(0.48 \pm 0.15)(P<0.05)$ (Figure 3A). The FVC of the extended care group $(0.56 \pm 0.12)$ also was significantly increased compared with that in the usual care group $(0.49 \pm 0.11)(P<0.05)$ (Figure 3B). The $\mathrm{FEV}_{1} / \mathrm{FVC}$ of the extended care group $(0.69 \pm 0.14)$ showed an obvious increase compared with the usual care group $(0.62 \pm 0.13)$ $(P<0.05)$ (Figure 3C). These results indicated that extended care contributes to improve the ventilation function of patients with COPD.

\section{Extended care reduces the acute exacerbation rates of patients with COPD} As shown in Table 6, after intervention, the acute exacerbation rate of COPD patients in the extended care group was lower $(4 / 70,5.7 \%)$ than that in the usual care group $(18 / 70$, $25.7 \%$ ), which indicated that the extended care contributed to control the disease progress of patients with $\operatorname{COPD}(P<0.05$; Figure 4A).

Table 4 Comparison of GHQ-I2 score between before intervention and after intervention for usual care group vs extended care group $(M \pm S D)$

\begin{tabular}{l|l|l|l|l|l}
\hline Items & Cases (N) & Groups & $\mathbf{M} \pm \mathbf{S D}$ & P-value \\
\cline { 4 - 5 } & & & Before intervention & After intervention & \\
\hline GHQ-12 scores & 70 & Usual care group & $7.99 \pm 1.09$ & $6.81 \pm 0.95$ & $>0.05$ \\
& 70 & Extended care group & $9.36 \pm 1.33$ & $2.73 \pm 0.59$ & $<0.05$ \\
& 70 & $T$-value & 0.49 & 11.55 & \\
& 70 & $P$-value & $>0.05$ & $<0.05^{\mathrm{a}}$ & \\
\hline
\end{tabular}

Note: aAfter intervention, the comparison of extended care with usual care on activity score $(P<0.05)$.

Abbreviations: GHQ-12, 12-item General Health Questionnaire; M, mean. 
Table 5 Comparison of pulmonary function between before intervention and after intervention for usual care group vs extended care group $(M \pm S D)$

\begin{tabular}{|c|c|c|c|c|c|}
\hline Group & Intervention & $\begin{array}{l}\text { Usual care group } \\
\text { (70 cases) }\end{array}$ & $\begin{array}{l}\text { Extended care } \\
\text { group ( } 70 \text { cases) }\end{array}$ & $T$-value & $P$-value \\
\hline \multirow[t]{2}{*}{$\mathrm{FEV}_{1} \%(\mathrm{M} \pm \mathrm{SD})$} & Before intervention & $0.46 \pm 0.17$ & $0.45 \pm 0.18$ & 0.41 & $>0.05$ \\
\hline & After intervention & $0.48 \pm 0.15$ & $0.57 \pm 0.09^{a}$ & 6.34 & $<0.05$ \\
\hline \multirow[t]{2}{*}{ FVC\% $(M \pm S D)$} & Before intervention & $0.47 \pm 0.12$ & $0.48 \pm 0.13$ & 0.41 & $>0.05$ \\
\hline & After intervention & $0.49 \pm 0.11$ & $0.56 \pm 0.12^{\mathrm{b}}$ & 8.56 & $<0.05$ \\
\hline \multirow[t]{2}{*}{$\mathrm{FEV}_{\mathrm{I}} / \mathrm{FVC}(\mathrm{M} \pm \mathrm{SD})$} & Before intervention & $0.59 \pm 0.14$ & $0.58 \pm 0.15$ & 0.79 & $>0.05$ \\
\hline & After intervention & $0.62 \pm 0.13$ & $0.69 \pm 0.14^{c}$ & 9.91 & $<0.05$ \\
\hline
\end{tabular}

Notes: ${ }^{\mathrm{a} A f t e r}$ intervention, the comparison of the extended care group with the usual care group on $\mathrm{FEV},(P<0.05)$. ${ }^{\mathrm{b}} \mathrm{After}$ intervention, the comparison of the extended care group with the usual care group on FVC $(P<0.05)$. 'After intervention, the comparison of the extended care group with the usual care group on $\mathrm{FEV} / \mathrm{FVC}(P<0.05)$. Abbreviation: M, mean.

\section{Extended care improves the blood gas levels of patients with COPD}

As shown in Table 6, after intervention, the extended care elevated the $\mathrm{PaO}_{2}(7.8 \pm 1.08 \mathrm{kPa})$ and reduced the $\mathrm{PaCO}_{2}$ $(6.09 \pm 0.93 \mathrm{kPa})$ of COPD patients, compared with those receiving usual care $\left(6.3 \pm 1.05 \mathrm{kPa}\right.$ for $\mathrm{PaO}_{2} ; 7.59 \pm 1.05 \mathrm{kPa}$ for $\mathrm{PaCO}_{2}$, respectively), which indicated that the extended care improved the blood gas levels of patients with COPD $(P<0.05$; Figure 4B).

\section{Discussion}

COPD is a chronic respiratory disease, which is the major cause of chronic morbidity and mortality worldwide. ${ }^{17} \mathrm{COPD}$ is mainly characterized by rapid development of irreversible
A

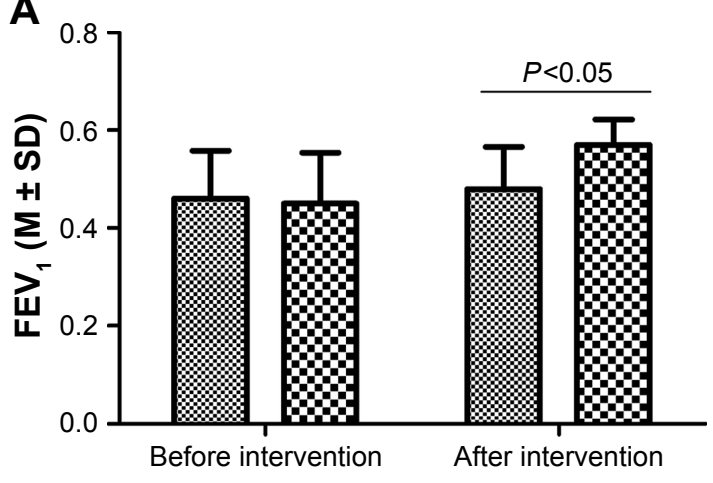

$\mathrm{C}$

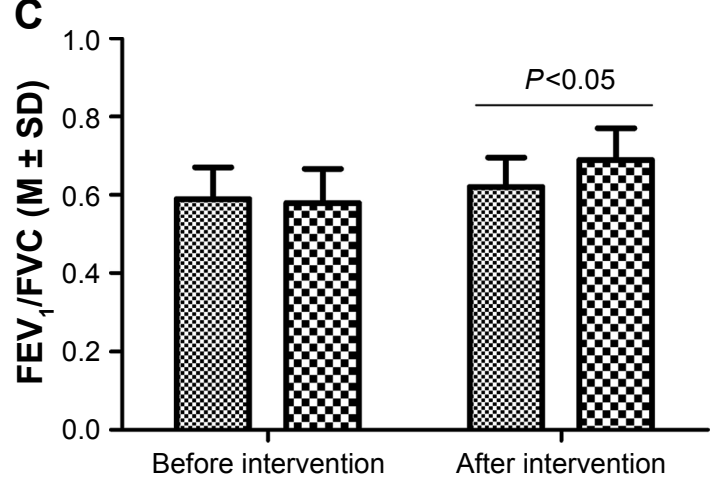

B

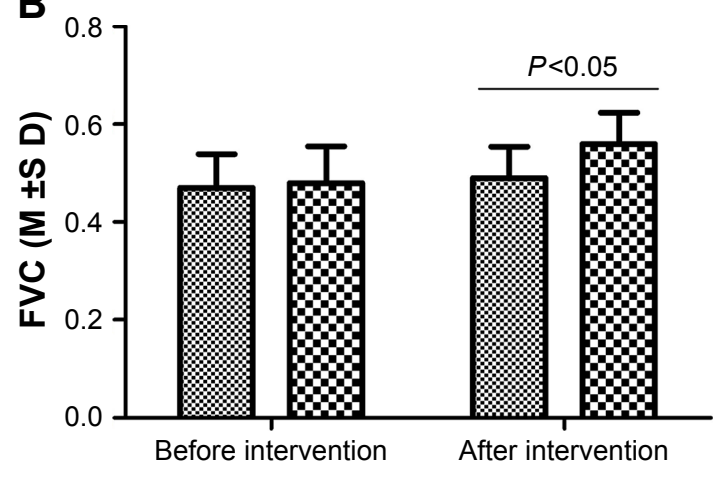

Q8 Usual care $\mathbf{0 x}$ Extended care

Figure 3 Effect of extended care and usual care on pulmonary function.

Notes: (A) After intervention, the value of $\mathrm{FEV}_{1}$ in the extended care group was higher than that in the usual care group ( $\left.P<0.05\right)$. (B) After intervention, the FVC in the extended care group was improved compared with the usual care group $(P<0.05)$. (C) After intervention, the FEV, /FVC of the extended care group showed an increasing trend compared with the usual care group $(P<0.05)$.

Abbreviation: M, mean. 
Table 6 Comparison of acute exacerbation rates and blood gas after intervention for usual care group vs extended care group (M \pm SD)

Comparison of acute exacerbation rates in two groups

\begin{tabular}{|c|c|c|c|c|}
\hline Groups & $\mathbf{N}$ (cases) & Acute exacerbation (\%) & No acute exacerbation (\%) & $P$-value \\
\hline $\begin{array}{l}\text { Usual care group } \\
\text { Extended care group }\end{array}$ & $\begin{array}{l}70 \\
70\end{array}$ & $\begin{array}{l}18(25.7) \\
4(5.7)\end{array}$ & $\begin{array}{l}52(74.3) \\
66(94.3)\end{array}$ & 0.001 \\
\hline \multicolumn{5}{|c|}{ Comparison of blood gas analysis in two groups } \\
\hline $\begin{array}{l}\text { Groups } \\
\text { Usual care group } \\
\text { Extended care group }\end{array}$ & $\begin{array}{l}\mathbf{N} \text { (cases) } \\
70 \\
70\end{array}$ & $\begin{array}{l}\mathrm{PaO}_{2}(\mathbf{k P a}) \\
6.3 \pm 1.05 \\
7.8 \pm 1.08^{\mathrm{a}}\end{array}$ & $\begin{array}{l}\mathrm{PaCO}_{2}(\mathbf{k P a}) \\
7.59 \pm 1.05 \\
6.09 \pm 0.93^{\mathrm{b}}\end{array}$ & $\begin{array}{l}P \text {-value } \\
0.001\end{array}$ \\
\hline
\end{tabular}

Notes: after intervention, the comparison of extended care with usual care on activity score $(P=0.00 \mathrm{I})$. ${ }^{\mathrm{b}} \mathrm{After}$ intervention, the comparison of extended care with usual care on activity score $(P=0.00 \mathrm{I})$.

Abbreviations: $\mathrm{M}$, mean; $\mathrm{PaCO}_{2}$, carbon dioxide partial pressure; $\mathrm{PaO}_{2}$, oxygen partial pressure.

airflow limitation, ${ }^{18}$ which is exacerbated by acute inflammatory insults such as lung infections (viral and bacterial) and air pollutants. ${ }^{3}$ Extended care is widely regarded as an essential element of high-quality health services, which can improve the patient's health outcomes, reduce the possibility of emergency and decrease the rates of acute hospitalization. ${ }^{6,19}$ At present, the study of extended care in China is just beginning to be promoted, which lacks considerable data.

The SGRQ is designed to measure health impairment in patients with asthma and COPD. In this study, we found all three aspects: activity ability, clinical symptoms and the effect of COPD to patients' daily lives, and the scores of the extended care group were all lower than those in the usual care group, which suggested that extended care contributed to control the disease progression of COPD. We believe that compared with usual care, the extended care helps patients understand the disease, elevate their ability to deal with the disease, coordinate with the treatment and strengthen the preventive measures. Previous study also shows that the extended care can reduce the number of hospitalized patients, prolong the time interval of rehospitalization, reduce medical expenses and improve their quality of patients. ${ }^{20} \mathrm{We}$ noticed that the extended care can significantly mitigate the clinical symptoms of COPD patients, indicating that the extended care promoted the disease rehabilitation of COPD patients. It has been suggested that the systematic rehabilitation of COPD patients with endurance training and respiratory muscle function training can effectively improve the symptoms of dyspnea in patients, enhance the ability of exercise tolerance, alleviate their psychological barriers and improve their quality of life. ${ }^{20}$

The GHQ-12 questionnaire is a self-rated questionnaire with a high applicability in the judgment of the patient's own condition (psychological well-being).${ }^{14}$ In this study,
A

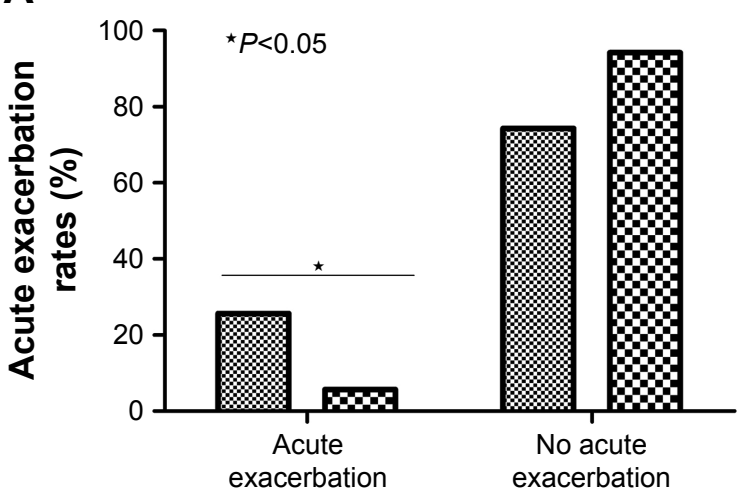

Program
B

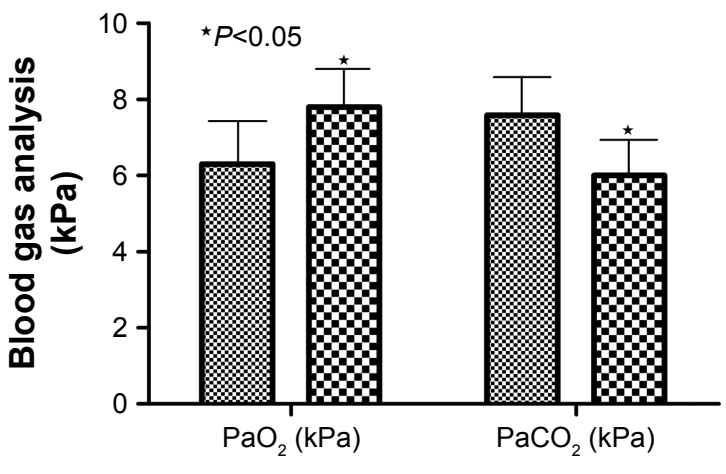

Program

Usual care Extended care

Figure 4 Effect of extended care and usual care on acute exacerbation rate and blood gas levels of COPD patients.

Notes: $(A)$ The acute exacerbation rate of COPD patients in the extended care group was lower than that in the usual care group $(P<0.05)$. (B) The extended care elevated the level of $\mathrm{PaO}_{2}$ and reduced the level of $\mathrm{PaCO}_{2}$ of COPD patients compared with usual care $(P<0.05)$.

Abbreviations: $\mathrm{PaCO}_{2}$, carbon dioxide partial pressure; $\mathrm{PaO}_{2}$, oxygen partial pressure. 
the rehabilitation and quality of life of the COPD patients in the extended care group were better than those in the usual care group, showing that the extended care improved the mental health status of patients with COPD. Research shows that extended care can increase the patient's psychological satisfaction, establish the confidence to overcome the disease, which not only improve the treatment effect of patients and strengthen the compliance of rehabilitation training, and actively promote the improvement of the quality of life of patients. ${ }^{7}$ COPD patients with disease progression will inevitably increase the symptoms of dyspnea, resulting in increased body metabolism. If it is not enough for energy at this time, it will inevitably lead to decreased weight of patients and malnutrition, and respiratory muscle structure and function will be affected. ${ }^{21}$ However, providing the extended care on COPD patients can effectively improve the nutritional status and promote the quality of life of COPD patients. In this study, we also found that extended care contributes to improve the ventilation function of patients with COPD. Home oxygen therapy is one of the indispensable means of treating COPD, and extended care can ensure the continuity and normality of home oxygen therapy, which is helpful for improvement of lung function. ${ }^{22}$

In addition, this study showed that the extended care reduced the possibility of acute exacerbations in patients with COPD. We believe that the own health awareness of patients with COPD in stable period can be improved after a series of continuous health education of extended care, which reduced the number of hospitalizations caused by acute exacerbation significantly. Extended care can strengthen the follow-up process with the patient's family communication so that the family members can fully understand the importance of social support for the rehabilitation of patients, which help patients in the process of rehabilitation maintain a positive attitude. Furthermore, we found that extended care elevated the level of $\mathrm{PaO}_{2}$ and reduced the level of $\mathrm{PaCO}_{2}$ in COPD patients compared with usual care, suggesting that extended care not only can alleviate the physical and mental burden of patients but also directly improve blood gas levels of COPD patients. Previous study shows that the extended care is beneficial to ensure the patient compliance to lung function rehabilitation training, family oxygen therapy, drug therapy and breathing training, thus promoting the arterial oxygen pressure levels and decreasing the levels of $\mathrm{PaCO}_{2} \cdot{ }^{23}$

There are several inadequacies in the study. First, the hospital nurses failed to communicate effectively with the community nurses where the patient is located, which leads to that the patient cannot get further guidance via the community nurses. Second, the study is limited by the observation time ( 3 months). Third, the study only involves some functional indicators and lacks the economic indicators and other data analyses. Fourth, the patients included in this study were all Chinese patients, which would result in selection bias from geographical and ethnic origin. Finally, the team was not blinded and hence there may be a risk of assessor bias, and some of the outcomes were self-reported, which leads to reporting bias. So, it is necessary to carry out a more deep study to further assess the efficacy of extended care to COPD patients.

\section{Conclusion}

Extended care improves the quality of life of patients with COPD after discharge, which is conducive to the rehabilitation of respiratory function and the psychological health of patients.

\section{Acknowledgment}

This study was supported by grant from the Scientific Research Plan projects of Shaanxi Province Education Department, China (No 17JK0661).

\section{Disclosure}

The authors report no conflicts of interest in this work.

\section{References}

1. Yoon HK, Park YB, Rhee CK, Lee JH, Oh YM, Ym O; Committee of the Korean COPD Guideline 2014. Summary of the chronic obstructive pulmonary disease clinical practice guideline revised in 2014 by the Korean academy of tuberculosis and respiratory disease. Tuberc Respir Dis. 2017;80(3):230-240.

2. Rosa F, Bagnasco A, Aleo G, Kendall S, Sasso L. Resilience as a concept for understanding family caregiving of adults with chronic obstructive pulmonary disease (COPD): an integrative review. Nurs Open. 2017; $4(2): 61-75$.

3. Laratta CR, van Eeden S. Acute exacerbation of chronic obstructive pulmonary disease: cardiovascular links. Biomed Res Int. 2014;2014: 528789.

4. Cwikel J, Abdelgani A, Goldsmith JR, Quastel M, Yevelson II. Two-year follow up study of stress-related disorders among immigrants to Israel from the Chernobyl area. Environ Health Perspect. 1997;105(Suppl 6): $1545-1550$.

5. Zorc JJ, Scarfone RJ, Li Y, et al; Randomized trial. Scheduled follow-up after a pediatric emergency department visit for asthma: a randomized trial. Pediatrics. 2003;111(3):495-502.

6. van Walraven C, Oake N, Jennings A, Forster AJ. The association between continuity of care and outcomes: a systematic and critical review. J Eval Clin Pract. 2010;16(5):947-956.

7. Haggerty JL, Reid RJ, Freeman GK, Starfield BH, Adair CE, McKendry R. Continuity of care: a multidisciplinary review. BMJ. 2003; 327(7425):1219-1221.

8. Coleman EA, Boult C; American Geriatrics Society Health Care Systems Committee. Improving the quality of transitional care for persons with complex care needs. J Am Geriatr Soc. 2003;51(4):556-557. 
9. Hui E, Ma HM, Tang WH, et al. A new model for end-of-life care in nursing homes. J Am Med Dir Assoc. 2014;15(4):287-289.

10. Montes de Oca M, López Varela MV, Laucho-Contreras ME, et al; en nombre del equipo del estudio PUMA. Classification of patients with chronic obstructive pulmonary disease according to the Latin American Thoracic Association (ALAT) staging systems and the global initiative for chronic obstructive pulmonary disease (GOLD). Arch Bronconeumol. 2017;53(3):98-106.

11. Vestbo J, Hurd SS, Agustí AG, et al. Global strategy for the diagnosis, management, and prevention of chronic obstructive pulmonary disease: GOLD executive summary. Am J Respir Crit Care Med. 2013;187(4): 347-365

12. Bellinger CR, Peters SP. Outpatient chronic obstructive pulmonary disease management: going for the GOLD. J Allergy Clin Immunol Pract. 2015;3(4):471-478.

13. Cleutjens F, Spruit MA, Ponds R, et al. The impact of cognitive impairment on efficacy of pulmonary rehabilitation in patients with COPD. $J$ Am Med Dir Assoc. 2017;18(5):420-426.

14. Aydin IO, Uluşahin A. Depression, anxiety comorbidity, and disability in tuberculosis and chronic obstructive pulmonary disease patients: applicability of GHQ-12. Gen Hosp Psychiatry. 2001;23(2):77-83.

15. Liu S, Chen J, He Y, et al. Comparative effectiveness of six Chinese herb formulas for acute exacerbation of chronic obstructive pulmonary disease: protocol for systematic review and network meta-analysis. BMJ Open. 2017;7(8):e17099.

16. Vogelmeier CF, Criner GJ, Martinez FJ, et al. Global strategy for the diagnosis, management and prevention of chronic obstructive lung disease 2017 report: GOLD executive summary. Respirology. 2017 22(3):575-601.
17. Hong Y, Lee JS, Yoo KH, et al. Implications of emphysema and lung function for the development of pneumonia in patients with chronic obstructive pulmonary disease. Tuberc Respir Dis (Seoul). 2016;79(2): 91-97.

18. Xiao B, Wang M, Hu X, Li J, Wang F, Sun J. Antibiotic de-escalation principle in elderly patients with chronic obstructive pulmonary disease complicated with severe pneumonia. Exp Ther Med. 2017; 13(4): 1485-1489.

19. Popejoy LL, Moylan K, Galambos C. A review of discharge planning research of older adults 1990-2008. West J Nurs Res. 2009;31(7) 923-947.

20. Naylor MD, Brooten DA, Campbell RL, Maislin G, McCauley KM, Schwartz JS. Transitional care of older adults hospitalized with heart failure: a randomized, controlled trial. J Am Geriatr Soc. 2004;52(5): 675-684.

21. Sarioglu N, Alpaydin AO, Coskun AS, Celik P, Ozyurt BC, Yorgancioglu A. Relationship between BODE index, quality of life and inflammatory cytokines in COPD patients. Multidiscip Respir Med. 2010;5(2):84-91.

22. Kanervisto M, Paavilainen E, Heikkilä J. Family dynamics in families of severe COPD patients. J Clin Nurs. 2007;16(8):1498-1505.

23. Doğan U, Ovayolu N. The effects of health education given by nurses to COPD patients on the daily oxygen concentrator usage time. Adv Respir Med. 2017;85(1):15-21.
International Journal of COPD

\section{Publish your work in this journal}

The International Journal of COPD is an international, peer-reviewed journal of therapeutics and pharmacology focusing on concise rapid reporting of clinical studies and reviews in COPD. Special focus is given to the pathophysiological processes underlying the disease, intervention programs, patient focused education, and self management protocols.

\section{Dovepress}

This journal is indexed on PubMed Central, MedLine and CAS. The manuscript management system is completely online and includes a very quick and fair peer-review system, which is all easy to use. Visit http://www.dovepress.com/testimonials.php to read real quotes from published authors. 